\title{
Supplement to
}

\section{Synchronizing early Eocene deep-sea and continental records - new cyclostratigraphic age models from the Bighorn Basin Coring Project}

Thomas Westerhold $^{1}$, Ursula Röhl ${ }^{1}$, Roy Wilkens ${ }^{2}$, Phil Gingerich ${ }^{3}$, Will Clyde ${ }^{4}$, Scott Wing ${ }^{5}$, Gabe Bowen ${ }^{6}$, Mary Kraus ${ }^{7}$

\footnotetext{
${ }^{1}$ MARUM - University of Bremen, Bremen, 28359, Germany

${ }^{2}$ Hawaii Institute of Geophysics \& Planetology, University of Hawaii, Honolulu, HI, 96822, U.S.A.

${ }^{3}$ Museum of Paleontology, University of Michigan, Ann Arbor, Michigan 48109-1079, U.S.A.

${ }^{4}$ Department of Earth Sciences, University of New Hampshire, 56 College Rd., Durham, NH 03824, U.S.A.

${ }^{5}$ Department of Paleobiology, P.O. Box 37012; National Museum of Natural History, Smithsonian Institution, Washington, D.C. 20013 U.S.A.

${ }^{6}$ Department of Geology \& Geophysics, University of Utah, Salt Lake City, UT, 84112, U.S.A.

${ }^{7}$ Department of Geological Sciences, University of Colorado at Boulder, UCB 399; Boulder, CO80309, U.S.A.
} 


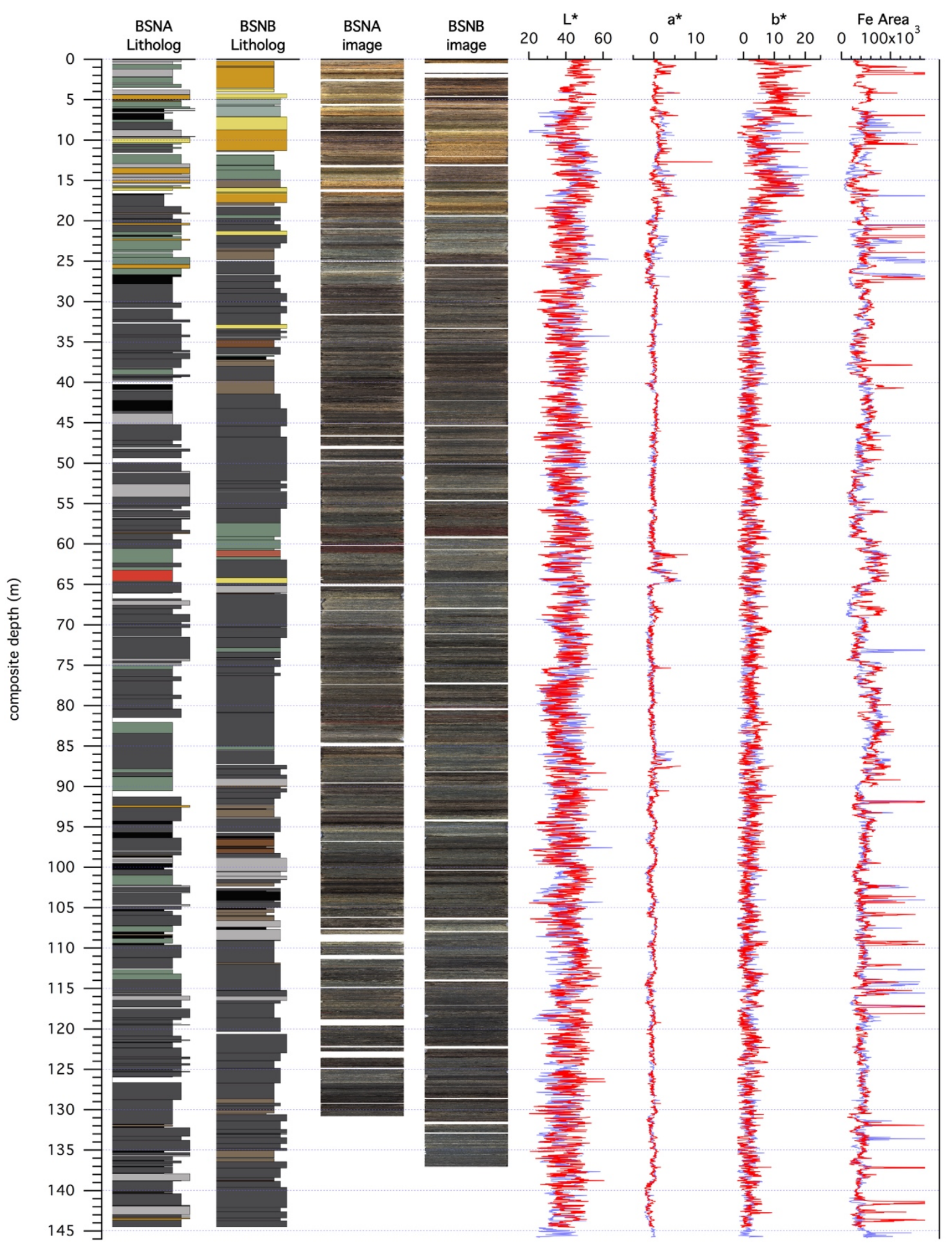

Figure S1: Raw data for Basin Substation (BSN) drill cores. From left to right against depth: Lithology logs for BSN $A$ and B; core scan images; Minolta Color scan LStar, AStar and BStar data (BSN A - red; BSN B - blue); XRF core scanning intensity for Iron Fe (Area) (BSN A - red; BSN B - blue). 


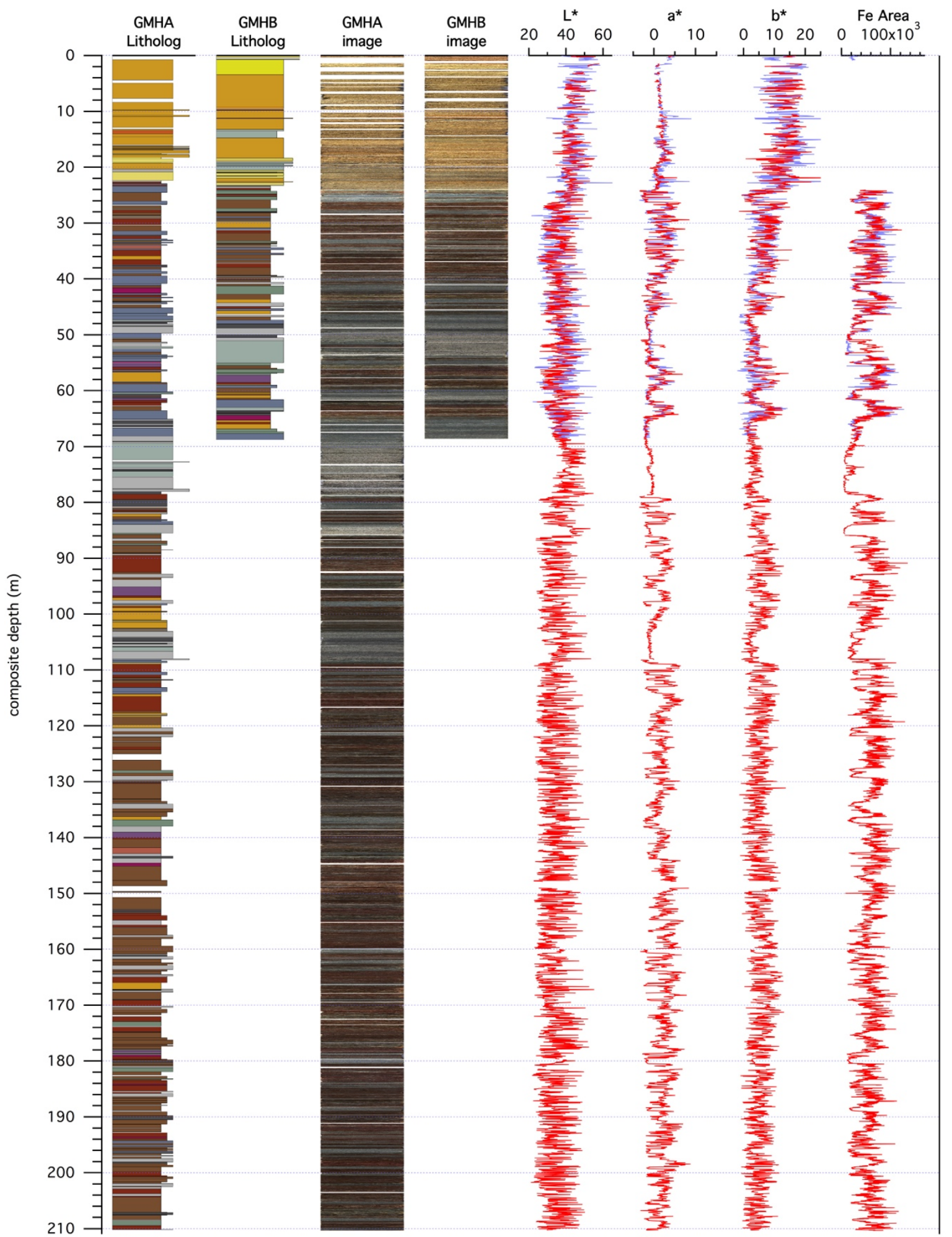

Figure S2: Raw data for Gilmore Hill (GMH) drill cores, for details see figure S1. 


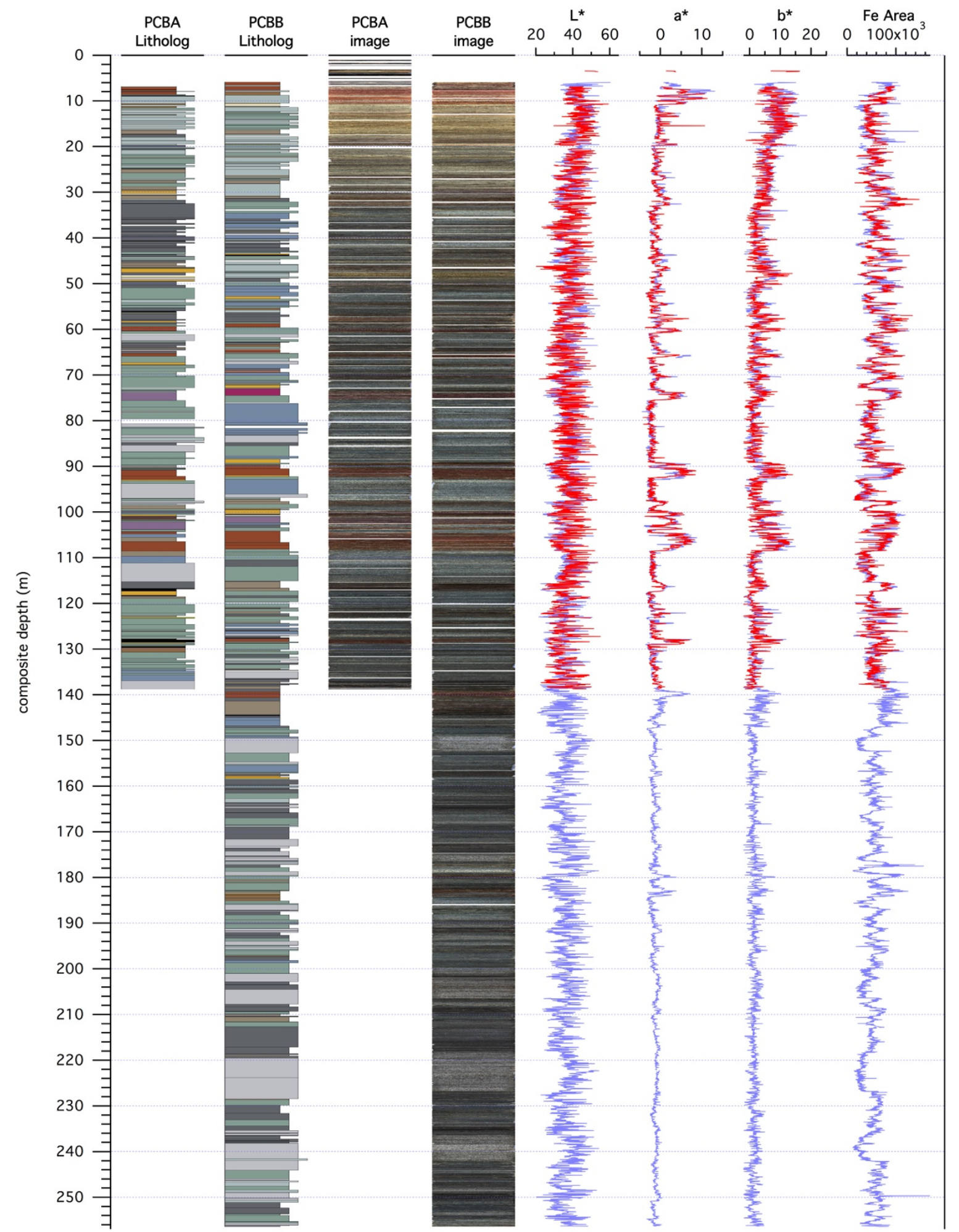

Figure S3: Raw data for Polecat Bench (PCB) drill cores, for details see figure S1. 

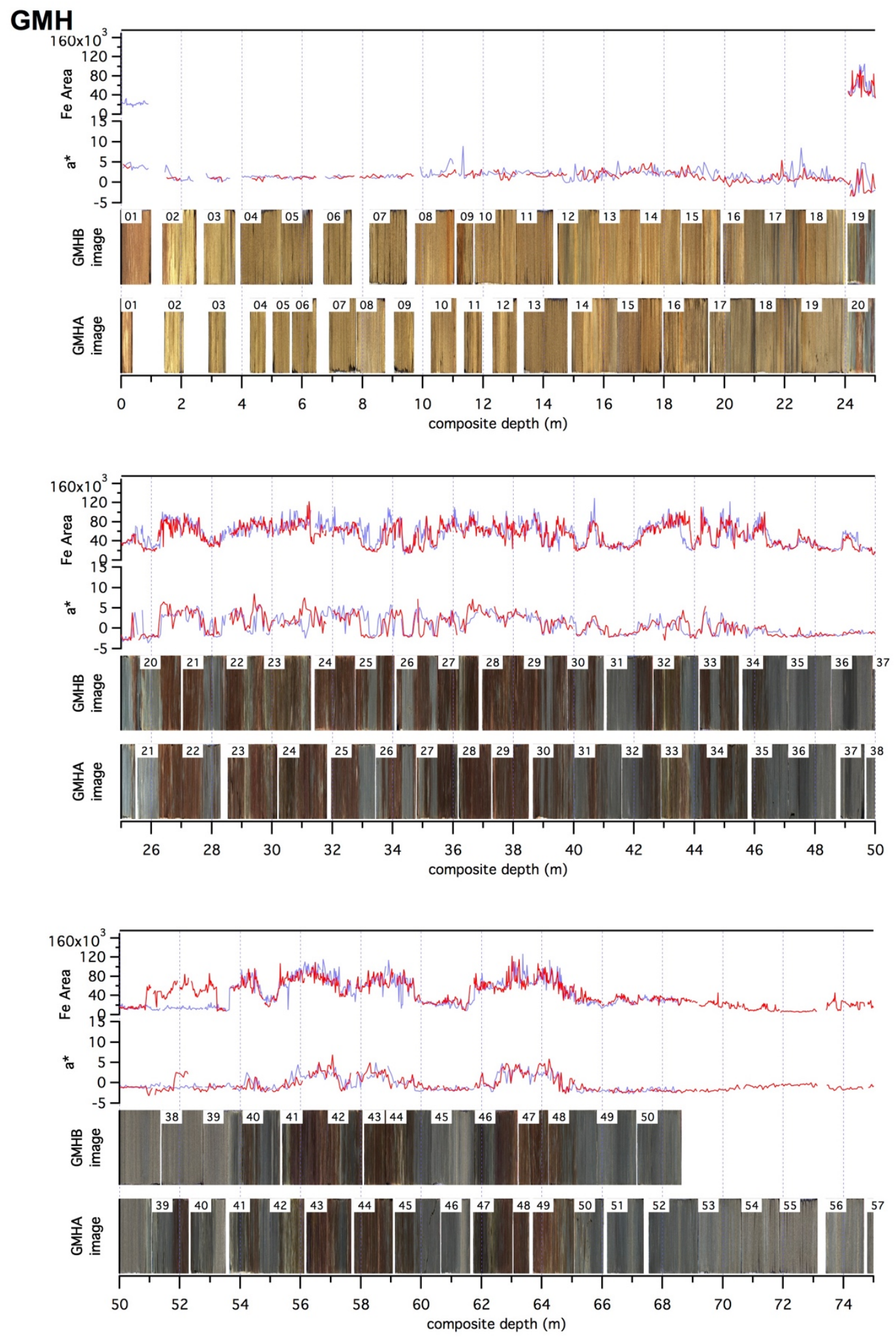

Figure S4: Composite depth plots for GMH. From bottom to top in each panel given are the core image for A and B hole, the $a^{*}$ and XRF Fe intensity data (GMH A - red, GMH B - blue) on composite depth med from 0-25, 25-50 and 50-75 med. Deeper than 75 mcd there is no parallel hole to correlate to. 


\section{BSN}
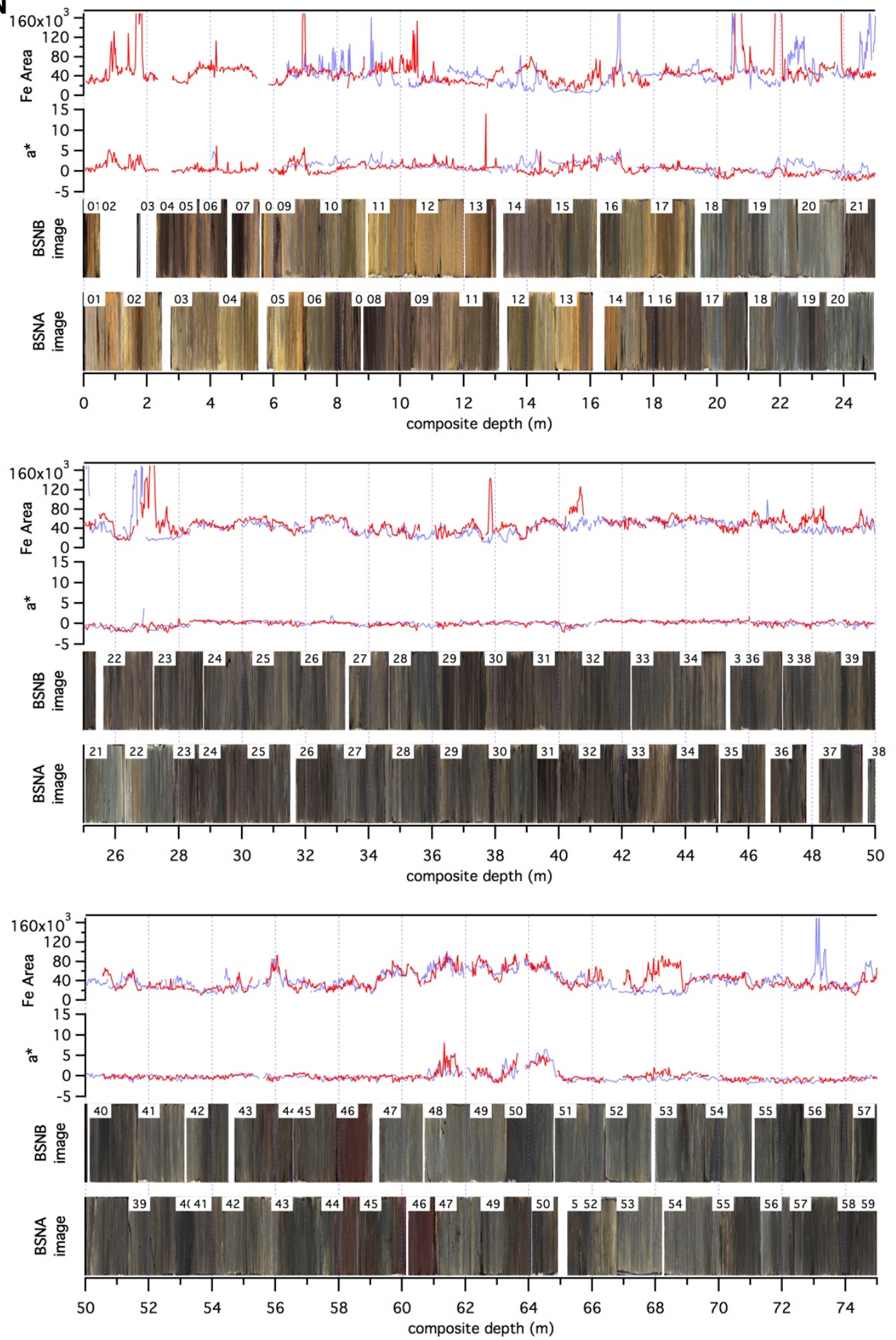

Figure S5a: Composite Depth plots for BSN. For details see figure S4. 


\section{BSN}
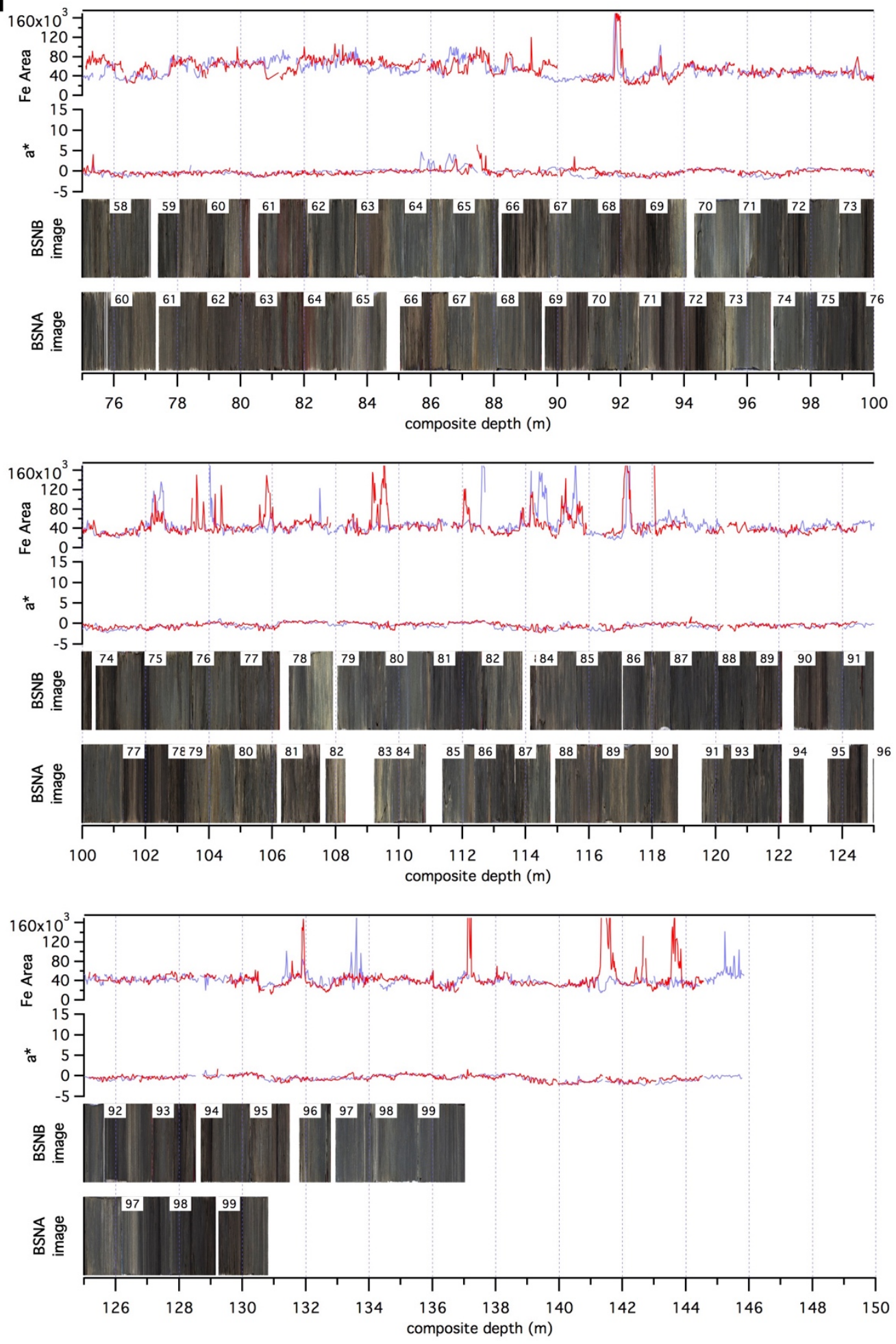

Figure S5b: Composite Depth plots for BSN continued. For details see figure S4. 


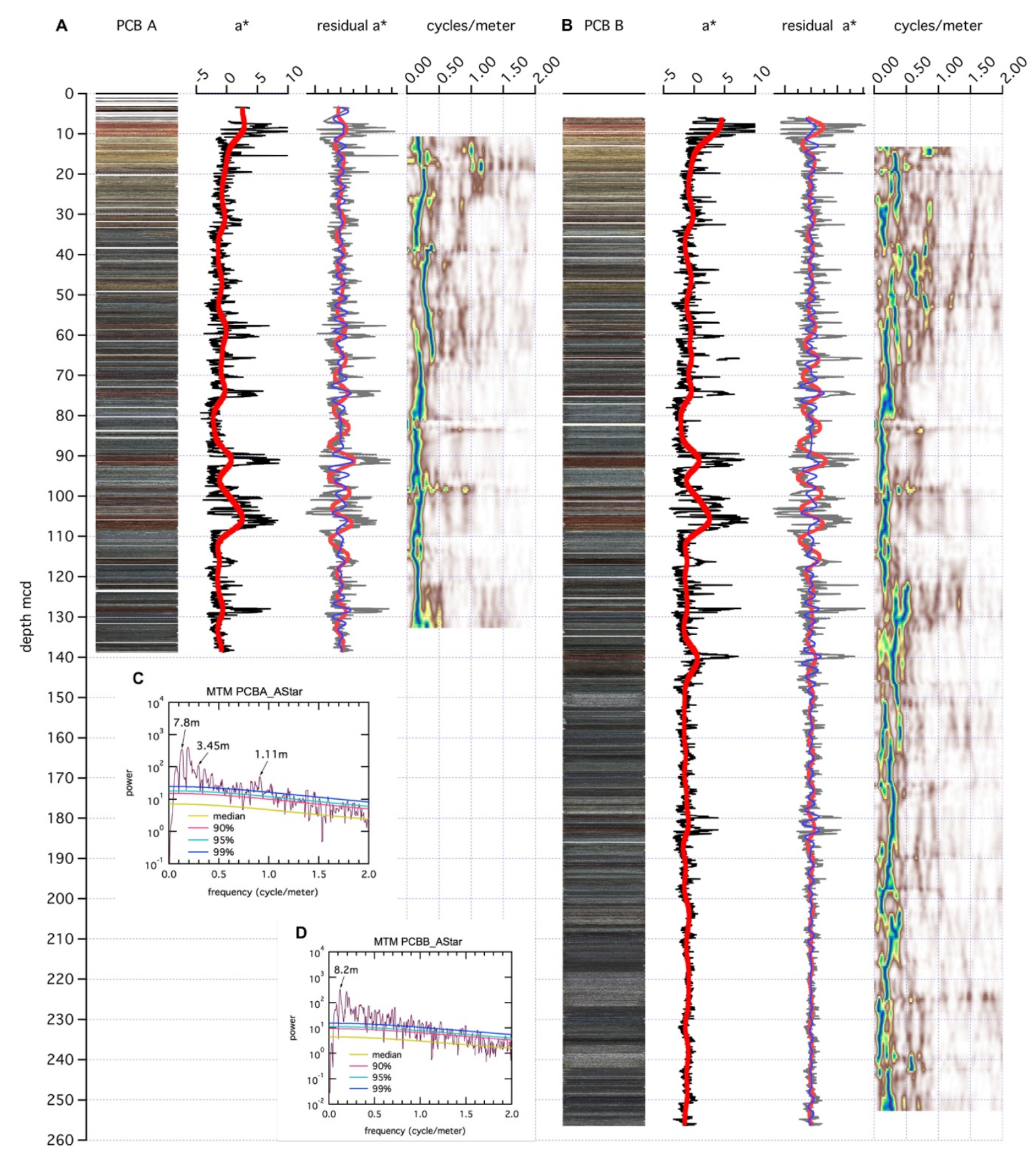

Figure S6: PCB spectral analysis on a* data from PCB A (A) and PCB B (B). Shown here core scan images, a* (black line) with trend (thick red line) that is removed for spectral analysis, the residual a* after trend removal, two Gaussian filters of the dominant cycles $(8 \mathrm{~m}, 3.5 \mathrm{~m})$, evolutive spectral plot to study changes in cyclicity and sedimentation rates, (C) and (D) figures show the MTM-Power spectra for PCB A and PCB B a*data. 


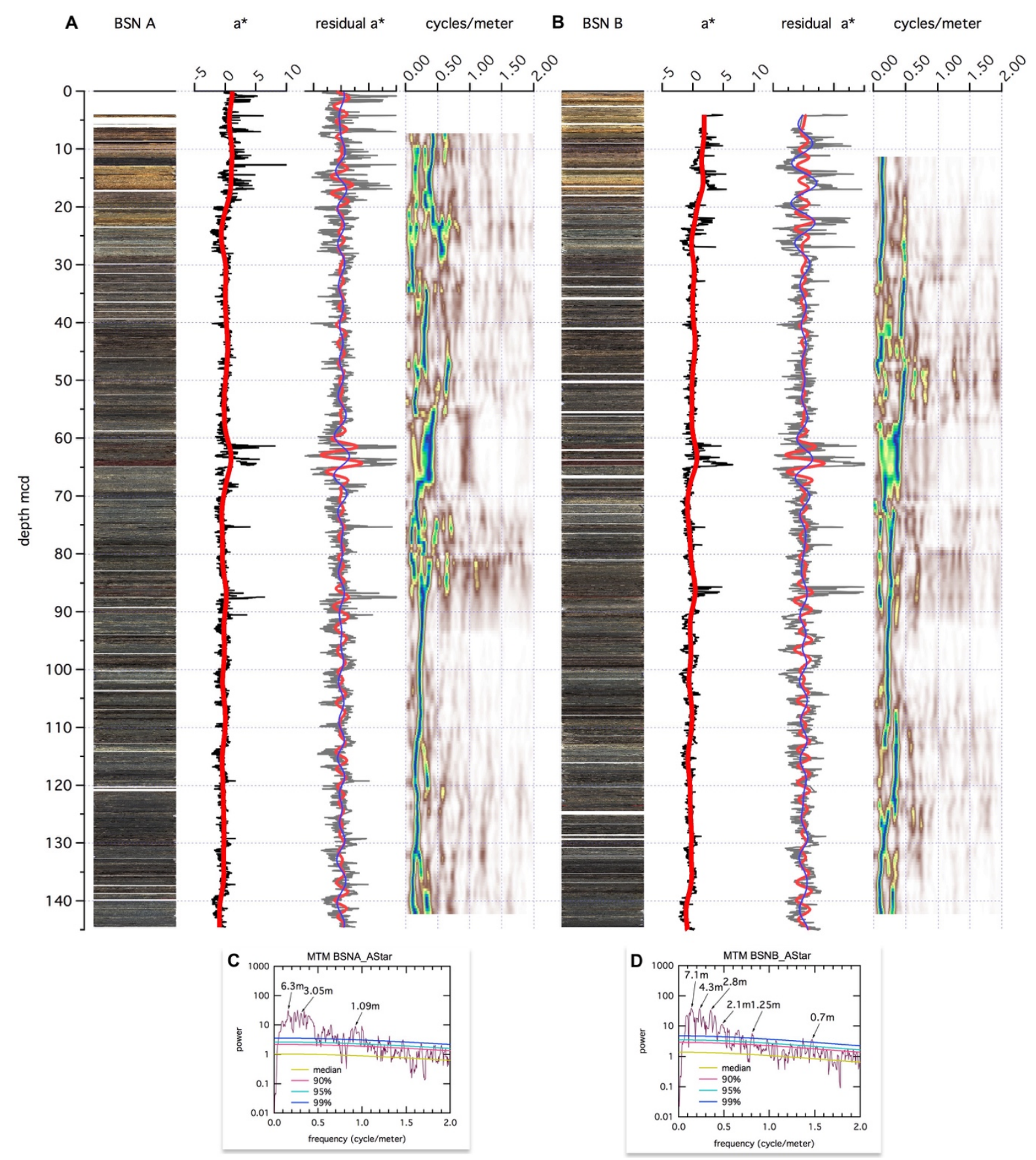

Figure S7: BSN spectral analysis figure for $a^{*}$ data, for details see as figure S6. 


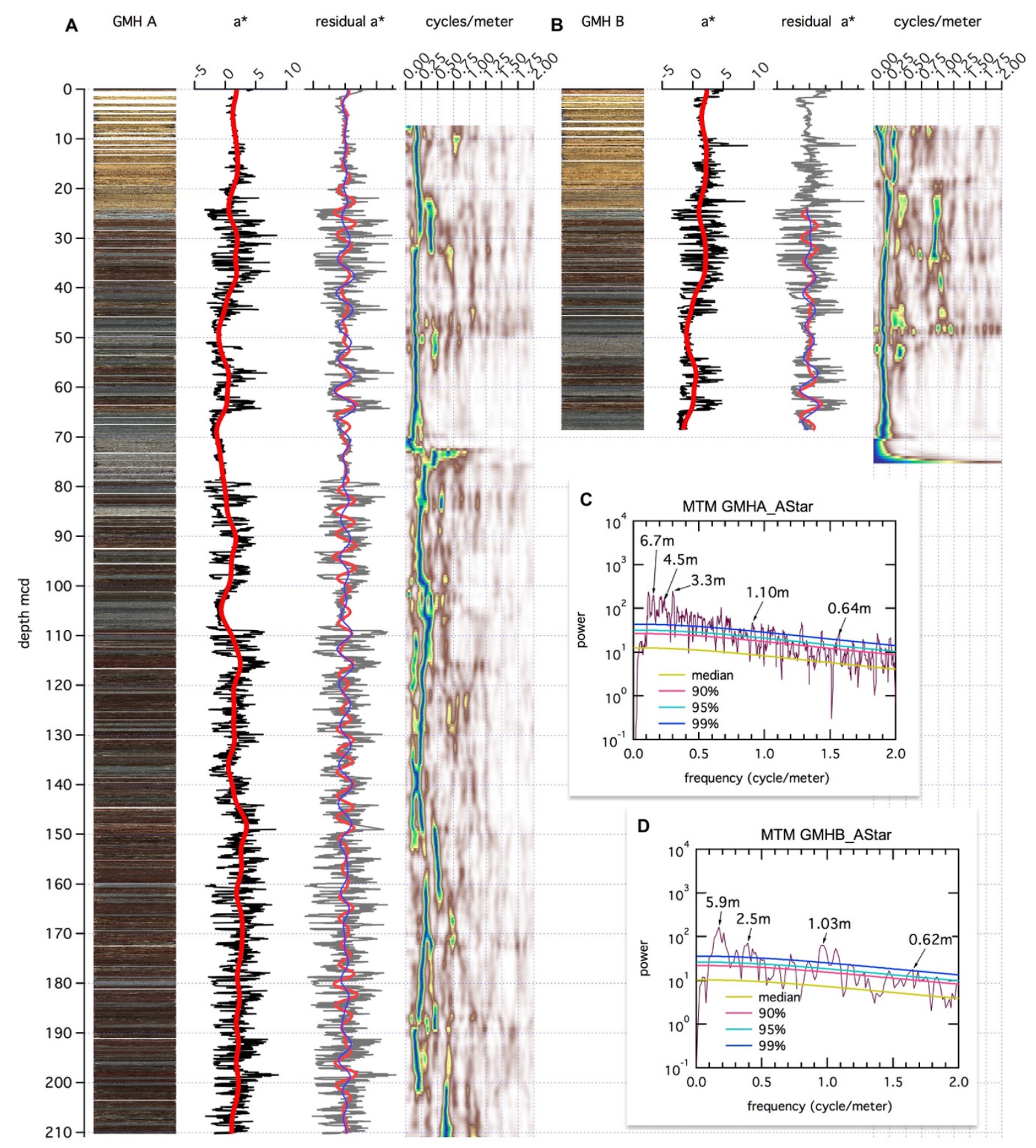

Figure S8: GMH spectral analysis figure for a* data, for details see as figure S6. 


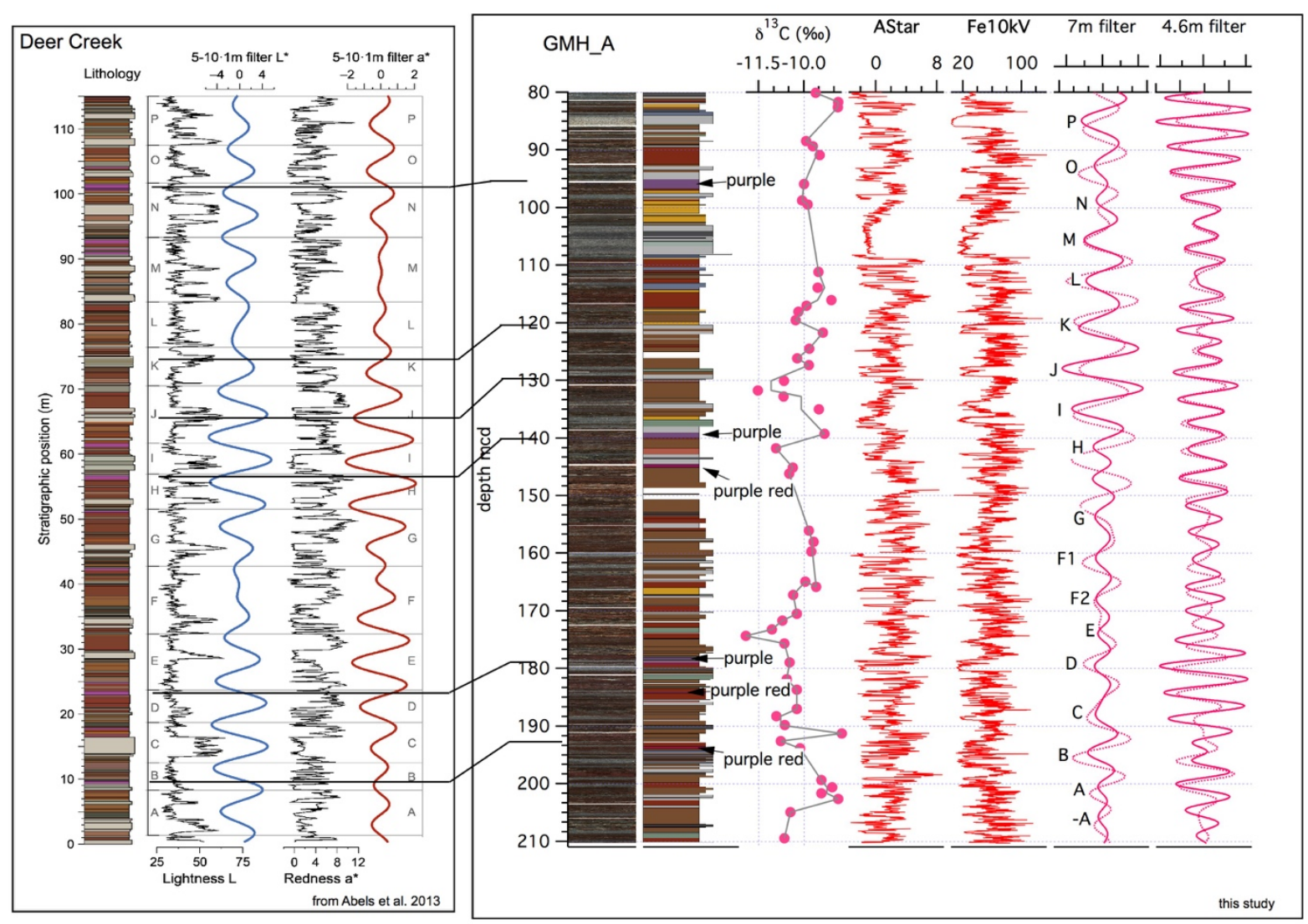

Figure S9: GMH correlation to the Deer Creek section (Abels et al. 2013). On the left panel Abels et al. 2013 Deer Creek section lithology with $L^{*}$ and a* data. On the right GMH A images, lithology, $\delta^{13} \mathrm{C}$ data, $a^{*}, \mathrm{XRF} F \mathrm{Fe}$ and filter of cycles with cycle letters. First order correlation was done by the purple beds and the thickness of strata between them. Subsequently the precession cycles were labelled accordingly. 


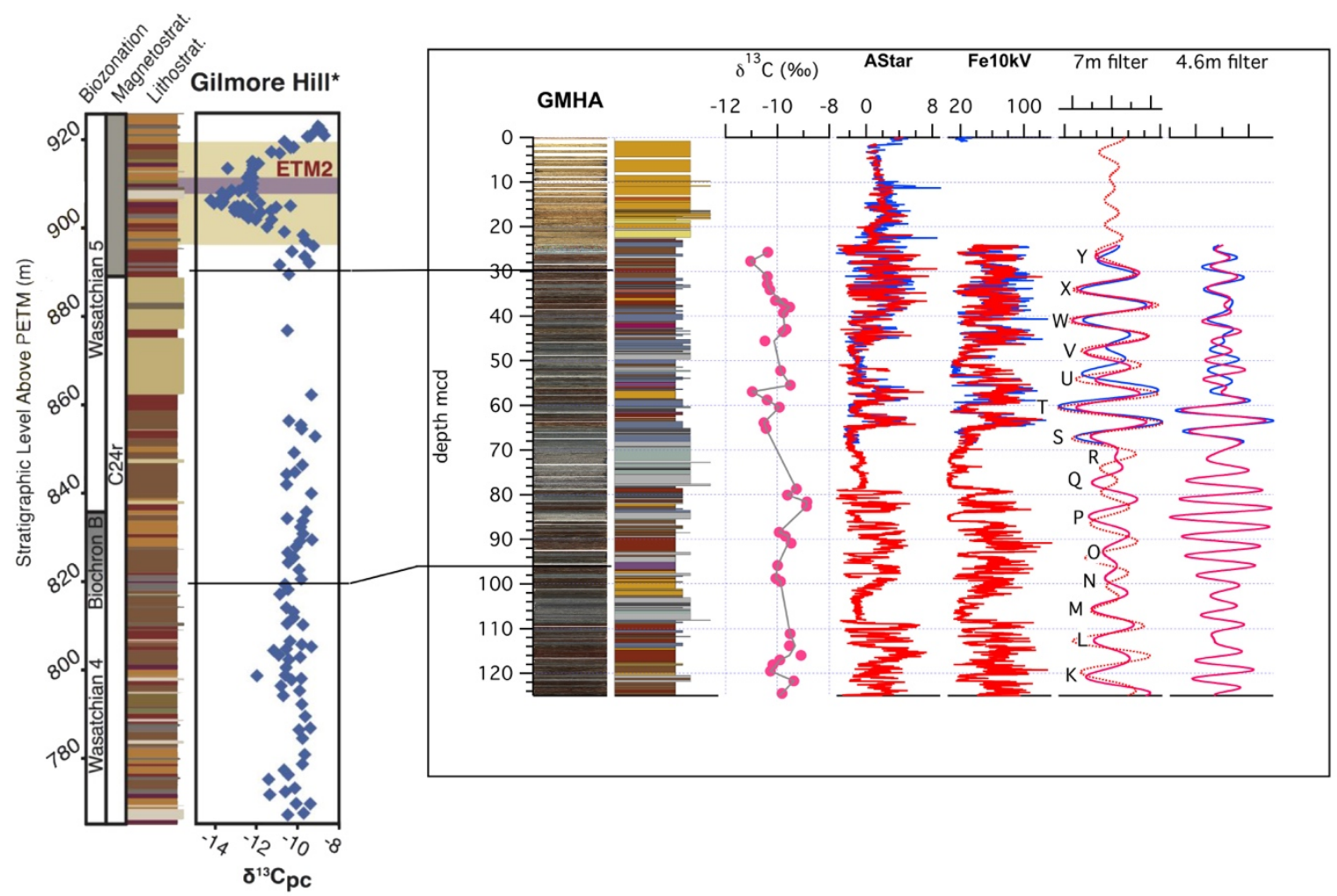

Figure S10: GMH correlation to Gilmore Hill section (DAmbrosia et al., 2017). On the left DAmbrosia et al., 2017 GMH section lithology with d13C data. On the right GMH A images, lithology, $\delta^{13} \mathrm{C}$ data, $\mathrm{a}^{*}, \mathrm{XRF}$ Fe and filter of cycles with cycle letters. First order correlation was done based on field observations. The GMH outcrop and the drillcore have about the same elevation and beds are gently dipping towards the core, thus the ELMO CIE is expected to be in the top 20-30 meters of the core where the sandstone is. Trend toward lower d13 $\mathrm{C}$ values right below the sandstone could be the very beginning of the CIE. The purple bed at 96 meters in the GMH core is correlated to the purple bed at $820 \mathrm{~m}$ in the outcrop. Precession cycles were labelled accordingly, see main text. 


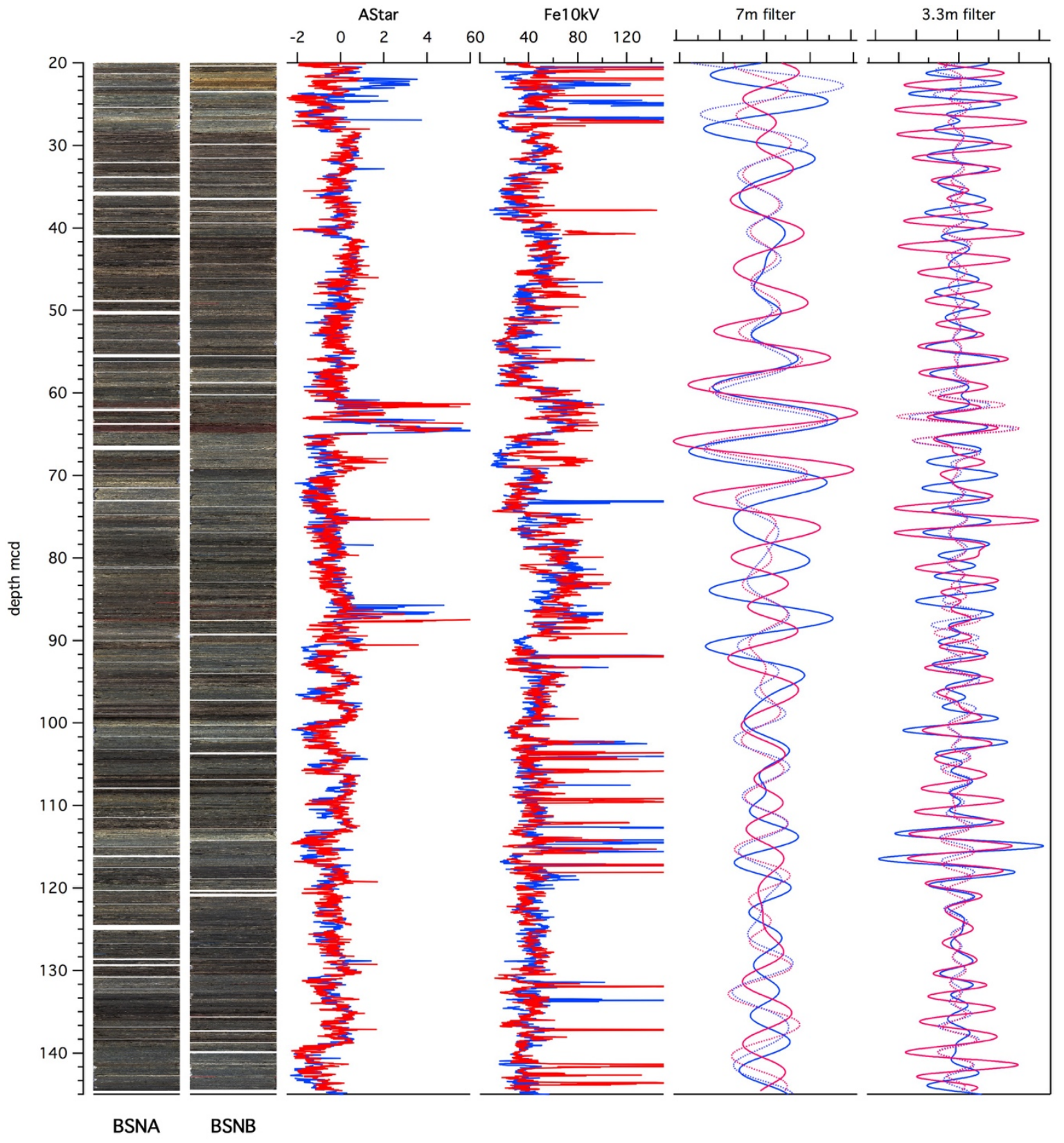

Figure S11: Extracted cycles in BSN drill cores. From left to right against depth: BSN A and B core images, $a^{*}$ data, XRF Fe data, Gaussian filter of $7 \mathrm{~m}$ cycles, Gaussian filter of $3.3 \mathrm{~m}$ cycles (A - red, B - blue). Note: the precession related $7 \mathrm{~m}$ cycle does not give consistent results over the entire drill core. 

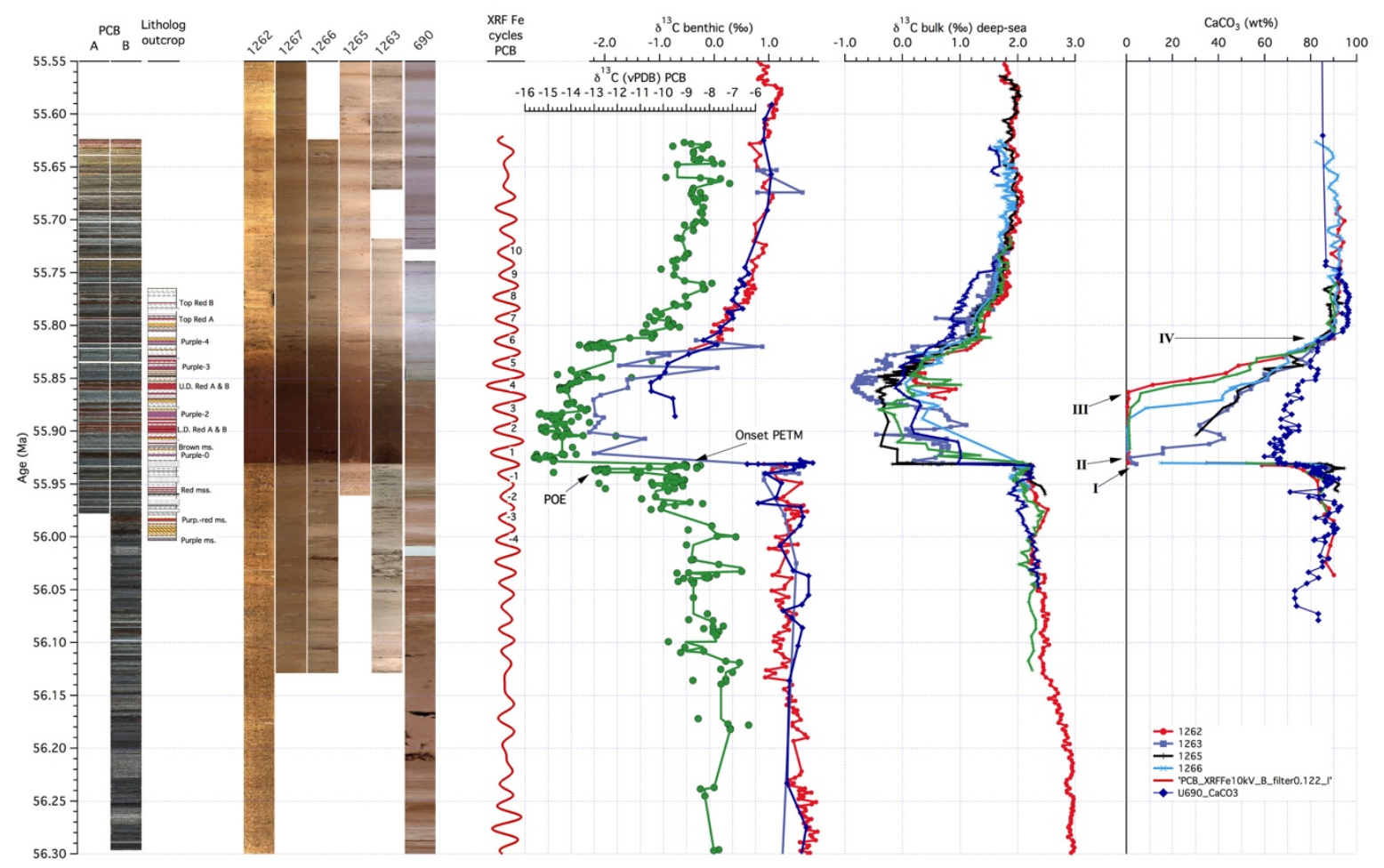

Figure S12: Overview for the Paleocene-Eocene Thermal Maximum (PETM) data from deep-sea records and the terrestrial Polecat Bench (PCB) drill core against age. Core images and lithology log (Gingerich et al., 2006) for PCB, core images of ODP Sites 1262, 1267, 1266, 1265, 1263 and 690 (aligned from left to right according to the water depth from deep to shallow), extracted Gaussian filter of the PCB XRF Fe intensity data, stable carbon isotope data from PCB soil nodules (Bowen et al., 2015) and the deep sea benthic foraminifera and bulk sediment (690 -Bains et al., 1999; Leg 208 - Zachos et al., 2005), and carbonate content (690 - Farley and Eltgroth, 2003; Leg 208 - Zachos et al., 2005). Letters indicate horizons as identified by Zachos et al., (2005) adjusted to the new age model for the deep-sea sites. 


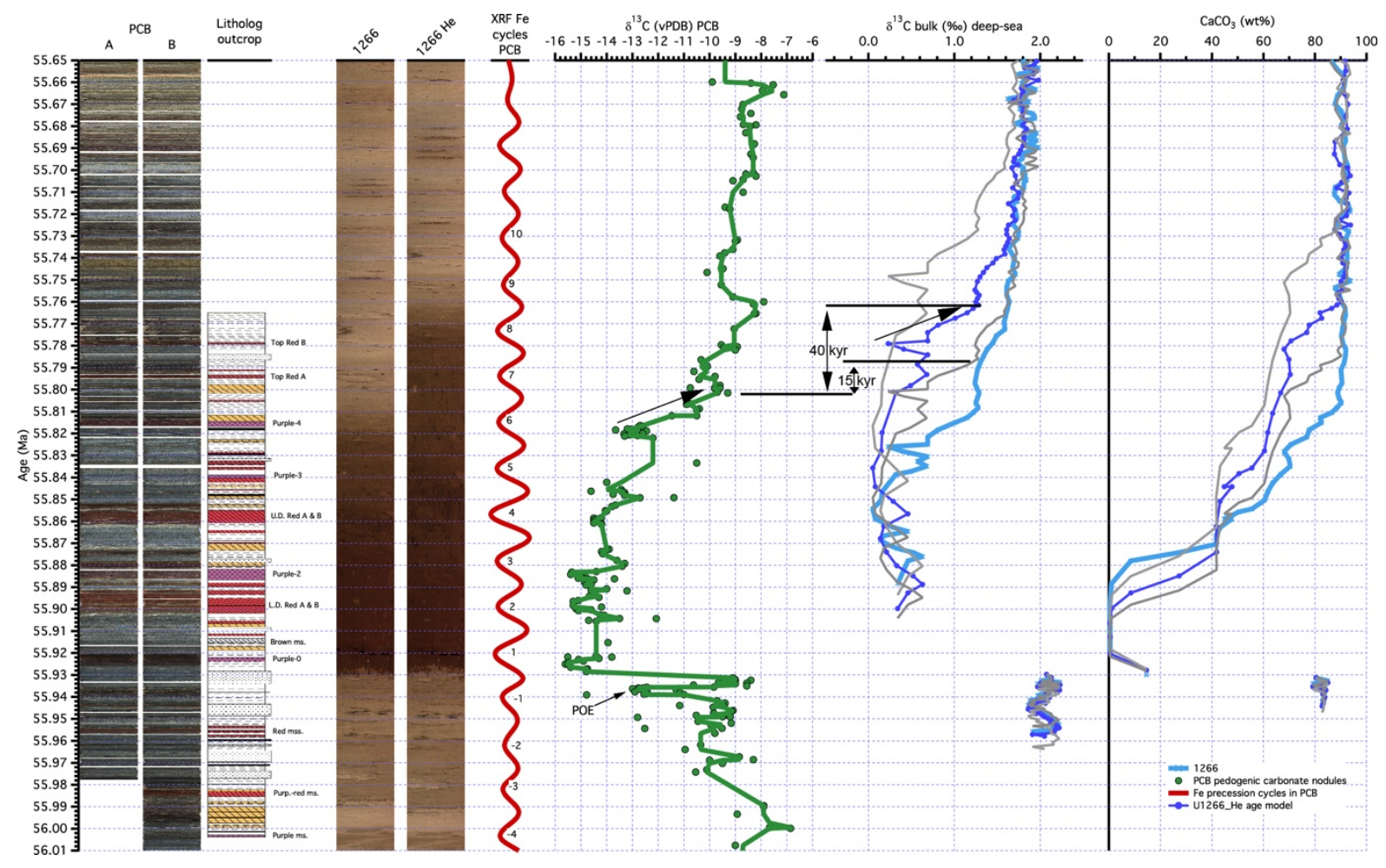

Figure S13: Comparing the updated cyclostratigraphic age model with the extraterrestrial ${ }^{3} \mathrm{He}$ age model of ODP 1266 (Murphy et al., 2010) for the PETM interval. Core images and lithology log (Gingerich et al., 2006) for PCB, core images of 1266 on cyclostratigraphy and ${ }^{3} \mathrm{He}$ age model, extracted Gaussian filter of the PCB XRF Fe intensity data, stable carbon isotope data from PCB soil nodules (Bowen et al., 2015), bulk sediment d13C and carbonate content data (Zachos et al., 2005) on cyclostratigraphy (light blue) and ${ }^{3} \mathrm{He}$ age model (dark blue, grey lines mark the upper and lower uncertainty in the age model). 